\title{
The effect of staggered
}

\section{administration of zinc sulfate on the pharmacokinetics of oral cephalexin}

Yi Ding, Yan-Yan Jia, Fan Li, Wen-Xing Liu, Cheng-Tao Lu, Yan-Rong Zhu, Jing Yang, Li-Kun Ding, Lin Yang \& Ai-Dong Wen

Department of Pharmacy, Xijing Hospital of the Fourth Military Medical University, Xi'an, China
Correspondence

Professor Ai-Dong Wen, Department of Pharmacy, Xijing Hospital of the Fourth Military Medical University, Xi'an 272000, China

Tel.: +86 2984775475

Fax: +86 2984775475

E-mail: adwen-2004@hotmail.com

Keywords

healthy volunteer, interaction, $\beta$-lactam antibiotics, pharmacokinetics, zinc

\section{Received}

14 April 2011

Accepted

26 August 2011

Accepted Article

Published Online

25 October 2011

\section{WHAT IS ALREADY KNOWN ABOUT} THIS SUBJECT

-Zinc supplementation is an important intervention against mortality from infectious disease.

- Many patients using zinc supplementation will also be prescribed antimicrobials at some time.

- Recently, an inhibitory effect of zinc on the absorption of $\beta$-lactam antibiotics has been demonstrated in animal studies, but there has been no clinical assessment of this drug-nutrient interaction.

\section{WHAT THIS STUDY ADDS}

-Zinc sulfate dosing significantly impaired the bioavailability and decreased $T>$ MIC of cephalexin in healthy volunteers, which might lead to a clinical failure.

- The dosing recommendation is that zinc sulfate can be safely administered $3 \mathrm{~h}$ after a cephalexin dose.

\section{AIMS}

To investigate the effect of zinc sulfate on pharmacokinetics of cephalexin when administered concurrently or at strategically spaced dosing times designed to avoid the potential interaction in healthy volunteers.

\section{METHODS}

In this study, all subjects $(n=12)$ were randomized to receive the following four treatments, separated by a wash-out period of 7 days: cephalexin $500 \mathrm{mg}$ alone, concomitantly with zinc $250 \mathrm{mg}, 3 \mathrm{~h}$ after zinc $250 \mathrm{mg}$ or $3 \mathrm{~h}$ before zinc $250 \mathrm{mg}$.

\section{RESULTS}

All subjects completed the study safely. Zinc supplements administered concurrently with cephalexin significantly decreased the peak serum concentration $\left(C_{\max }\right)$, area under the plasma concentration-time curve from zero to infinity $\left(A \cup C_{0-\infty}\right)$ and the time for which the plasma concentration of the drug remained above the minimal inhibitory concentration of the pathogenic organism ( $T>$ MIC) of cephalexin [mean percentage decrease (95\% confidence intervals) of 31.05\% (22.09-40.01\%), 27.40\% (18.33-36.47\%) and 22.33\% (12.51-32.16\%), respectively; $P<0.05$ ] compared with administration of cephalexin alone. Also, administration of zinc $3 \mathrm{~h}$ before cephalexin decreased the $C_{\max }, \mathrm{AUC}_{0-\infty}$ and $T>\mathrm{MIC}$ of the drug compared with administration of cephalexin alone [mean percentage decrease ( $95 \%$ confidence intervals) of $11.48 \%(3.40-19.55 \%), 18.12 \%(9.63-26.60 \%)$ and $23.75 \%$ (14.30-33.20\%), respectively; $P<0.05]$. In contrast, the pharmacokinetics of cephalexin was not notably altered by administration of zinc $3 \mathrm{~h}$ after cephalexin dosing $(P>0.05)$.

\section{CONCLUSIONS}

The significant interaction between zinc and cephalexin might affect the clinical outcome of cephalexin therapy. The dosing recommendation is that zinc sulfate can be safely administered $3 \mathrm{~h}$ after a cephalexin dose. 


\section{Introduction}

Cephalexin is one of the major $\beta$-lactam antibiotics, with good activity against Gram-positive bacteria, such as Staphylococci spp. and Streptococci spp. After a $500 \mathrm{mg}$ oral dose, reported peak serum concentrations $\left(C_{\max }\right)$ of cephalexin are approximately $15-18 \mu \mathrm{g} \mathrm{ml}^{-1}$, with a half-life $\left(t_{1 / 2}\right)$ of approximately $1.2 \mathrm{~h}[1,2]$.

Following oral administration, the absorption of cephalexin is rapid, mediated by the di- and tripeptide intestinal transporters, as for many peptidomimetic drugs [3, 4]. Recently, data from laboratory studies have suggested that there is an inhibitory effect of zinc on the absorption of $\beta$-lactam antibiotics by inhibition of the peptide transporters $[5,6]$. As $\beta$-lactam class antibiotics provide a timedependent bactericidal activity, the time for which the plasma concentration of the drug remains above the minimal inhibitory concentration of the pathogenic organism ( $T>M I C)$ is the pharmacokinetic/pharmacodynamic index that best predict their antibacterial efficacy $[7,8]$. Moreover, in vivo studies in laboratory rodents and humans have determined that best clinical efficacy is obtained when $T>$ MIC is obtained for $40-50 \%$ of the dosing interval in clinical settings and 70\% in an experimental model [7]. Thus, changes in the plasma concentrations due to drugzinc interaction may affect the clinical outcome of cephalexin therapy.

Zinc supplementation is being used increasingly in important fields of research, such as in the prevention of diarrhoea and pneumonia [9] and in achieving optimal growth [10]. Moreover, zinc supplementation is an enormously important intervention against mortality from infectious disease [11], and many patients using zinc supplementation will also be prescribed antimicrobials at some time. Clinically, zinc deficiency should be treated with zinc supplementation at four to five times the recommended dietary allowance $[12,13]$. As a result, if the combination of a high-dose zinc supplementation and cephalexin cannot be avoided, doses should be staggered to minimize this potential drug interaction. However, there is no currently clinical assessment for the interaction between zinc and $\beta$-lactam antibiotics.

It is therefore important to define a therapeutic time window within which a $\beta$-lactam antimicrobial can be co-administered with zinc. In the present four-way crossover study in healthy volunteers, we investigated whether zinc would alter the pharmacokinetics of cephalexin and, furthermore, demonstrated a reasonable scheme of zinc supplementation to prevent a zinc-drug interaction.

\section{Methods}

\section{Participants}

Male subjects were eligible for enrolment if they provided written informed consent and met the following criteria: age between 30 and 40 years, and body mass index $18-35 \mathrm{~kg} \mathrm{~m}^{-2}$. All subjects were found to be in good health prior to the study on the basis of medical history, physical examination and laboratory tests. The exclusion criteria were as follows: use of medications containing di- and trivalent cations (e.g. iron, zinc or calcium), zinc-containing multivitamins or over-the-counter medications within $48 \mathrm{~h}$ before the first dosing day of each study session; use of prescribed medications within 14 days of the study start; and previous allergy to any of the constituents of the pharmaceuticals administered during the trial.

\section{Study design}

This open, randomized, single-dose, four-way crossover study in 12 healthy male volunteers was conducted in accordance with Good Clinical Practice Guidelines and the Declaration of Helsinki, and the study protocol (Ethics Approval no. 2009L11722) was approved by the Institutional Review Board of Xijing Hospital, Xi'an, China.

The subjects were randomized to receive each of four dosing regimens separated by a wash-out period of 7 days. The regimens were as follows: cephalexin $500 \mathrm{mg}(250 \mathrm{mg}$ per capsule; Harbin pharmaceutical factory, Ltd, Harbin, China), alone (regimen A), concomitantly with zinc sulfate $250 \mathrm{mg}(50 \mathrm{mg}$ per tablet; immediate-release dose form, containing a total of $56 \mathrm{mg}$ elemental zinc; Huanghai pharmaceutical factory, Ltd, Jiangsu, China; regimen B), $3 \mathrm{~h}$ after zinc sulfate $250 \mathrm{mg}$ (regimen $\mathrm{C}$ ) or $3 \mathrm{~h}$ before zinc sulfate $250 \mathrm{mg}$ (regimen D).

All study medication was swallowed with $200 \mathrm{ml}$ of water at $08.00 \mathrm{~h}$. Subjects fasted from midnight the night prior to each dosing session, and food was restricted until $4 \mathrm{~h}$ after dosing with cephalexin, when a light standard meal was provided. Dinner was provided $10 \mathrm{~h}$ after dosing with cephalexin. Subjects abstained from mineral drinks, alcohol, caffeine-containing drinks and grapefruit juice from $48 \mathrm{~h}$ prior to the study start until $48 \mathrm{~h}$ after dosing on each dosing day.

This exploratory trial was performed in 12 healthy volunteers without a formal sample size estimation, because the number was considered sufficient to fulfil the objectives of the study. The investigation was performed in healthy men only, because there have been no reports of gender-specific differences in cephalexin pharmacokinetics.

\section{Pharmacokinetic sampling and bioanalysis}

Participants were instructed to remain in a sitting or standing position for at least $2 \mathrm{~h}$ after each dose throughout the study. With an indwelling angiocatheter inserted into a vein in the forearm, blood samples (approximately $3 \mathrm{ml}$ ) were taken at $0,15,30$ and $45 \mathrm{~min}, 1.0,1.5,2.0,2.5,4.0,5.0$, 6.5 and $8.0 \mathrm{~h}$ after administration (a first, standardized meal was allowed $4 \mathrm{~h}$ after dosing). All blood samples for cephalexin concentration analysis were immediately centrifuged and stored at $-70^{\circ} \mathrm{C}$ until assayed. 
Cephalexin concentrations were determined using the modified high-performance liquid chromatography method [14] on an Agilent 1200 series high-performance liquid chromatograph with a reversed-phase column (Promosil C $18 ; 150 \times 4.6 \mathrm{~mm} ; 5 \mu \mathrm{m}$ particle size) and a UV spectrophotometric detector. The chromatographic conditions were as follows: mobile phase, a mixture consisting of acetonitrile and $10 \mathrm{mmoll}^{-1}$ ammonium acetate solution $(10: 90, v / v)$; flow rate, $1 \mathrm{ml} \mathrm{min}{ }^{-1}$; column temperature, $40^{\circ} \mathrm{C}$; and wavelength, $260 \mathrm{~nm}$.

To $0.5 \mathrm{ml}$ of plasma sample mixed with $40 \mu \mathrm{l}$ internal standard (tinidazole) solution $\left(100 \mu \mathrm{g} \mathrm{ml}^{-1}\right)$, in $1.5 \mathrm{ml}$ microtubes, $0.2 \mathrm{ml}$ perchloric acid was added. The samples were extracted by vortex mixing for $30 \mathrm{~min}$ and centrifuged at high speed for $10 \mathrm{~min}$. A $50 \mu$ l volume of upper aqueous phase was injected into the column, and the retention time of cephalexin was $8.9 \mathrm{~min}$.

Standard curves were linear and provided a detection range from 0.3 to $50 \mathrm{\mu g} \mathrm{ml}^{-1}$. The correlation coefficient for the regression line of the standard solution was 0.999 . Quality-control samples of $0.5,4,20$ and $40 \mathrm{\mu g} \mathrm{ml}^{-1}$ were interspersed among the samples. The lower limit of quantification was $0.3 \mu \mathrm{g} \mathrm{ml}^{-1}$. The coefficient of variation for intraday precision was $4.75 \%$ and for interday precision $4.98 \%$.

\section{Safety evaluation}

Safety was assessed via physical examinations, electrocardiograms (ECGs), vital signs and clinical laboratory tests conducted at screening, before dosing at each treatment period and at the conclusion of the study. Adverse events were assessed with regard to severity (mild, moderate, severe and life threatening) and relationship (reasonably or possibly related, not reasonably or possibly related) to study treatments. Gastrointestinal intolerance was recorded as episodes of high gastric residual volume, emesis or diarrhoea.

\section{Pharmacokinetic data analysis}

The pharmacokinetic parameters of cephalexin were estimated using a noncompartmental method with the aid of the DAS program (Drugs and Statistics version 2.0, Chinese Pharmacological Society, Beijing, China). The maximal concentration $\left(C_{\max }\right)$ and the time to $C_{\max }\left(T_{\max }\right)$ were obtained directly from the original data. The terminal rate constant $\left(k_{\mathrm{e}}\right)$ was obtained by regression analysis of the log-linear portion of the concentration-time curve. The terminal halflife $\left(t_{1 / 2}\right)$ was calculated as $0.693 / \mathrm{k}_{\mathrm{e}}$. The area under the plasma concentration-time curve (AUC) to the last quantifiable concentration $\left(A \cup C_{0-8 h}\right)$ was determined by use of the linear trapezoidal rule. The AUC from zero to infinity $\left(A \cup C_{0-\infty}\right)$ was calculated by $A \cup C_{0-8 h}+C_{t} / k_{e}$, where $C_{t}$ is the last measured plasma concentration. The value of $T>$ MIC was determined for the previously reported $\mathrm{MIC}_{90}$ values for Staphylococcus aureus (methicillin sensitive; $4.0 \mu \mathrm{g} \mathrm{ml}^{-1}$ ) [15] and expressed as a percentage of the recommended dosing interval (6 h) [16].

\section{Statistical analysis}

The data are expressed as means $\pm \mathrm{SD}$, except for $T_{\max }$ data, which are presented as medians and range. Changes associated with zinc administration were assessed with use of 95\% confidence intervals of the percentage of intraindividual differences. Statistical calculations were performed with SPSS for Windows, version 16.0 (SPSS Inc, Chicago, IL, USA), and values of $P<0.05$ were considered significant. To describe differences in pharmacokinetic parameters between treatments, the results were evaluated by two-way ANOVA (subjects and treatments). The between-treatment $T_{\max }$ data were compared by use of the Wilcoxon signed rank test.

\section{Results}

All subjects tolerated the protocol well.There were no clinically important changes in blood pressure, pulse rate, ECG parameters or clinical laboratory parameters during the study. No drug sensitization could be detected. Gastrointestinal tolerance of antibiotics was good.

Cephalexin pharmacokinetic parameters for each group are provided in Table 1, and the decrease in bioavailability and $T>$ MIC when the regimens (B, C and D) were compared with administration of cephalexin alone (regimen A) are shown in Table 2. The mean plasma cephalexin concentration-time plots for the four treatment groups are shown in Figure 1.

Estimated pharmacokinetic parameters (Table 1) in our subjects who took cephalexin alone were similar to parameters reported by other investigators [1,2]. Compared with the effect of cephalexin alone, the effect of zinc supplements administered concurrently with cephalexin produced a marked decrease in the $C_{\max }, \mathrm{AUC}_{0-\infty}$ and $T>\mathrm{MIC}$ [mean decrease (95\% confidence interval) of $31.05 \%$ (22.09-40.01\%), $26.86 \%(17.91-35.81 \%)$ and $22.33 \%$ (12.51-32.16\%), respectively; $P<0.05]$. Likewise, administration of zinc $3 \mathrm{~h}$ before dosing with cephalexin decreased the $C_{\max }, A_{U} C_{0-\infty}$ and $T>$ MIC compared with the cephalexin alone treatment [mean percentage decrease ( $95 \%$ confidence interval) of $11.48 \%$ (3.40-19.55\%), $18.34 \%$ (10.03-26.65\%) and $23.75 \%$ (14.30-33.20\%), respectively; $P$ $<0.05]$. In contrast, the pharmacokinetics of cephalexin was not notably altered by administration of zinc $3 \mathrm{~h}$ after cephalexin dosing $(P>0.05)$. There was no significant difference in $t_{1 / 2}$ and $T_{\max }$ between the four regimens $(P>$ 0.05).

\section{Discussion}

The data from laboratory research have demonstrated a significant inhibitory effect of zinc on the absorption of 


\section{Table 1}

Pharmacokinetic parameters of cephalexin for the four treatment regimens

\begin{tabular}{|c|c|c|c|c|}
\hline \multirow[b]{2}{*}{ Parameter } & \multicolumn{4}{|c|}{ Treatment } \\
\hline & A & B & c & D \\
\hline$C_{\max }\left(\mu \mathrm{g} \mathrm{ml}^{-1}\right)$ & $\begin{array}{l}18.07 \pm 4.27 \\
(15.26-20.79)\end{array}$ & $\begin{array}{l}12.46 \pm 2.73^{*} \\
(10.73-14.20)\end{array}$ & $\begin{array}{l}16.00 \pm 4.06^{*} \\
(13.42-14.58)\end{array}$ & $\begin{array}{l}17.35 \pm 3.67 \\
(15.02-19.68)\end{array}$ \\
\hline$T_{\max }(\mathrm{h})$ & $1(0.75-2.5)$ & $1(0.25-1.5)$ & $1(0.75-1.5)$ & $1(0.75-1.5)$ \\
\hline$A \cup C_{0-\infty}\left(\mu \mathrm{g} \mathrm{h} \mathrm{ml}^{-1}\right)$ & $\begin{array}{l}41.97 \pm 6.04 \\
(38.14-45.81)\end{array}$ & $\begin{array}{l}30.47 \pm 3.52^{*} \\
(28.24-32.71)\end{array}$ & $\begin{array}{l}34.37 \pm 1.58^{*} \\
(33.37-35.37)\end{array}$ & $\begin{array}{l}41.13 \pm 6.62 \\
(36.93-45.34)\end{array}$ \\
\hline$t_{1 / 2}(\mathrm{~h})$ & $\begin{array}{l}1.50 \pm 0.58 \\
(1.13-1.87)\end{array}$ & $\begin{array}{l}1.13 \pm 0.27 \\
(0.96-1.30)\end{array}$ & $\begin{array}{l}1.65 \pm 0.79 \\
(1.14-2.15)\end{array}$ & $\begin{array}{l}1.28 \pm 0.26 \\
(1.12-1.45)\end{array}$ \\
\hline
\end{tabular}

Values are given as means \pm SD (95\% confidence intervals), with the exception of $T_{\max }$, for which median and minimum-maximum ranges are given. $n=12$. Treatments were as follows: (A) cephalexin $500 \mathrm{mg}$ administered alone; (B) cephalexin $500 \mathrm{mg}$ administered concurrently with zinc sulfate $250 \mathrm{mg}$; (C) zinc sulfate $250 \mathrm{mg}$ given $3 \mathrm{~h}$ before cephalexin $500 \mathrm{mg}$; and (D) cephalexin $500 \mathrm{mg}$ given $3 \mathrm{~h}$ before zinc sulfate $250 \mathrm{mg}$. *Values statistically different $(P<0.05)$.

\section{Table 2}

The percentage decrease in $C_{\max }, \mathrm{AUC}_{0-\infty}$ and $T>\mathrm{MIC}$ of cephalexin administered in regimens $\mathrm{B}, \mathrm{C}$ and $\mathrm{D}$, compared with administration of cephalexin alone

\begin{tabular}{|llll|}
\hline Parameter & B & C & Treatment \\
\hline $\boldsymbol{C}_{\max }\left(\mu \mathbf{g ~ m l}^{-1}\right)$ & $31.05 \%(22.09-40.01 \%)$ & $11.48 \%(3.40-19.55 \%)$ & D \\
\hline $\mathbf{A U C} \mathbf{C}_{0-\infty}\left(\mu \mathbf{~ h ~ m l}^{-1}\right)$ & $27.40 \%(18.33-36.47 \%)$ & $18.12 \%(9.63-26.60 \%)$ & $2.00 \%(-4.61$ to $12.61 \%)$ \\
$\boldsymbol{T}>\mathbf{M I C}(\%)$ & $22.33 \%(12.51-32.16 \%)$ & $23.75 \%(14.30-33.20 \%)$ & $1.92 \%(-12.81$ to $16.90 \%)$ \\
\hline
\end{tabular}

Values are given as percentages (95\% confidence intervals. $n=12$

$\beta$-lactam antibiotics $[5,6]$, but there has been no clinical assessment for this interaction. The present study was undertaken to investigate the effects of oral administration of zinc supplements on the pharmacokinetics and predicted clinical efficacy of cephalexin in healthy male volunteers.

Our study showed that the bioavailability $\left(C_{\max }\right.$ and $\left.A \cup C_{0-\infty}\right)$ of cephalexin were markedly reduced by zinc given concomitantly. As shown in previous in vivo studies, one of the mechanisms of the zinc-drug interaction is probably that zinc is a competitive inhibitor of peptide transporter 1 (PEPT1) [6], which is the transporter determining the oral bioavailability of $\beta$-lactam antibiotics [17]. Furthermore, zinc interacts with many kinds of proteins. For example, inhibitory effects of zinc on the intestinal transport of glucose [18], L-threonine [19] and folic acid [20] have been reported, which might lead to inhibition of the absorption of drugs, such as ceftibuten [5]. In contrast, divalent and trivalent pharmaceutical cations, such as, $\mathrm{Mg}^{2+}, \mathrm{Al}^{3+}, \mathrm{Fe}^{2+}, \mathrm{Zn}^{2+}$ and $\mathrm{Ca}^{2+}$, interact with new quinolone antibacterials [21-27], tetracycline antibiotics [28] or captopril [29] by chelation and reduce the intestinal absorption of these drugs. There is a possibility that the interaction between zinc and cephalexin is due to the chelation of drugs with zinc.

The objective of this study was to develop reasonable periods in which cephalexin and zinc can be administered

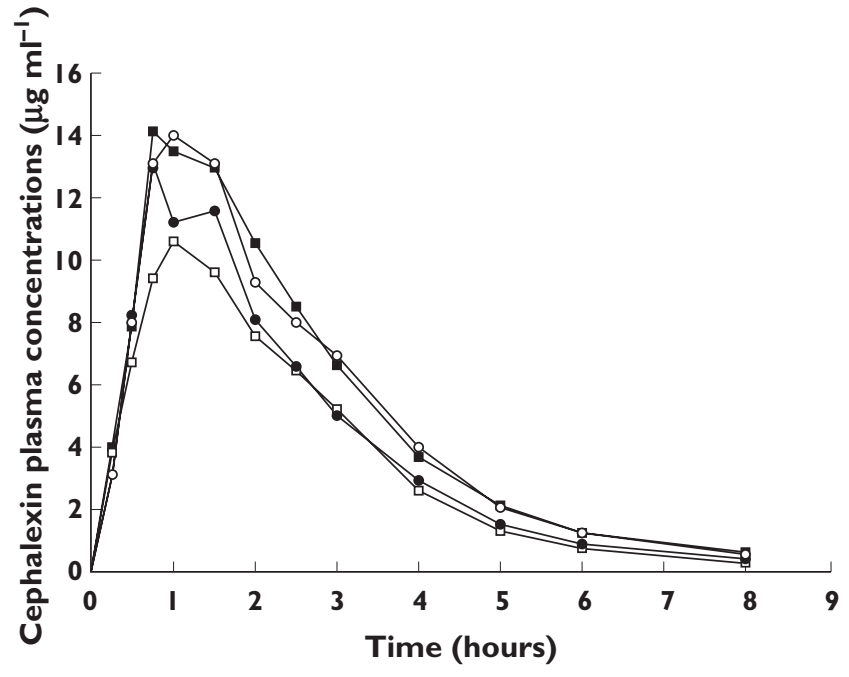

\section{Figure 1}

Mean plasma cephalexin concentration vs. time curves for cephalexin $500 \mathrm{mg}$ alone (A), cephalexin $500 \mathrm{mg}$ administered concurrently with zinc sulfate $250 \mathrm{mg}$ (B), zinc sulfate $250 \mathrm{mg}$ given $3 \mathrm{~h}$ before cephalexin $500 \mathrm{mg}(\mathrm{C})$ and cephalexin $500 \mathrm{mg}$ given $3 \mathrm{~h}$ before zinc sulfate $250 \mathrm{mg}$ (D) $(n=12)$. A ( $\square) ; \mathrm{B}(\square) ; \mathrm{C}(\bigcirc) ; \mathrm{D}(\mathrm{O})$ 
safely. Alternatively, it may be possible to reduce the extent of the interaction by separating the time of ingestion of the two drugs by $2 \mathrm{~h}$ or longer [22, 28]. In our study, however, the pharmacokinetics of cephalexin were still significant altered by administration of zinc $3 \mathrm{~h}$ before dosing with cephalexin, which is inconsistent with the results of a zinc-ceftibuten experiment in an animal model [5]. The reason for this discrepancy is still not clear. It is probable that inhibition by zinc of the intestinal transporter was still present when the cephalexin was administered, because the process of absorption of zinc sulfate tablets is relatively slow compared with the zinc solution administered to rats [5]. In all four regimens, using this dosage and formulation, our results have shown that averages of $T>$ MIC for Staphylococci were within the desired values (40-50\%) [7], but the significantly diminished $T>$ MIC that resulted from administration of zinc concurrently or $3 \mathrm{~h}$ before dosing with cephalexin should not be neglected. As the dose of cephalexin used in this study was the normal maximal dose employed for serious skin and soft tissue infections, the subjects receiving lower doses or with longer dosing intervals may suffer from a clinical failure [30], assuming that the $T>$ MIC was below the desired values due to the zincdrug interaction. In contrast, none of the pharmacokinetic parameters for cephalexin was significantly altered by zinc administered $3 \mathrm{~h}$ after cephalexin, since cephalexin had reached the maximal concentration $1-2 \mathrm{~h}$ after dosing. To conclude, the interaction with zinc could be almost completely avoided in all subjects in the study by giving the cephalexin dose $3 \mathrm{~h}$ after the zinc dose.

In the clinical setting, the recommended dietary allowance of elemental zinc for men is 11 and for women $8 \mathrm{mg}$ day $^{-1}$ [31], but zinc deficiency should be treated with zinc supplementation at four to five times the recommended dietary allowance $[12,13]$. In the present study, the doses of zinc sulfate used ( $250 \mathrm{mg} ; 56 \mathrm{mg}$ elemental zinc) were based on the highest doses likely to be administered on a single occasion for therapy. As a result, smaller doses would reasonably be expected to have less effect on absorption of cephalexin.

There are several limitations of the present investigation. First, only one preparation of zinc was assessed, but it is possible that study of different formulations may lead to different effects on pharmacokinetic results. Second, only two staggered dosing regimens were explored, so other possible regimens remain unknown. Third, other doses of zinc were not used in this study, so we do not know whether this effect is dose related. To the best of our knowledge, however, this is the first clinical study to investigate the interaction between zinc and cephalexin. The results will add important information to the study of interaction between drugs and mineral supplementation, and also help in better use of supplementation in patients.

In conclusion, significant reductions in bioavailability and $T>$ MIC occur with this combination, with an increased likelihood of therapeutic failure. Accordingly, on the basis of this study in healthy male volunteers, cephalexin should be administered $3 \mathrm{~h}$ before zinc sulfate in order to prevent an interaction.

\section{Competing Interests}

There are no competing interests to declare.

This work was supported by Department of Pharmacy, Xijing Hospital of the Fourth Military Medical University, Xi'an, Shaanxi, China. The study participants and nurses are kindly acknowledged for their invaluable help with this study.

\section{REFERENCES}

1 Bergan T, Midtvedt T, Erikssen J. Human pharmacokinetics of cephalexin. Pharmacology 1970; 4: 264-72.

2 Lode H, Stahlmann R, Koeppe P. Comparative pharmacokinetics of cephalexin, cefaclor, cefadroxil, and CGP 9000. Antimicrob Agents Chemother 1979; 16: 1-6.

3 Leibach FH, Ganapathy V. Peptide transporters in the intestine and the kidney. Annu Rev Nutr 1996; 16: 99-119.

4 Saito H, Terada T, Shimakura J, Katsura T, Inui K. Regulatory mechanism governing the diurnal rhythm of intestinal $\mathrm{H}+$ /peptide cotransporter 1 (PEPT1). Am J Physiol Gastrointest Liver Physiol 2008; 295: G395-402.

5 Okamura M, Terada T, Katsura T. Inhibitory effect of zinc on the absorption of beta-lactam antibiotic ceftibuten via the peptide transporters in rats. Drug Metab Pharmacokinet 2008; 23: 464-8.

6 Okamura M, Terada T, Katsura T, Saito H, Inui K. Inhibitory effect of zinc on PEPT1-mediated transport of glycylsarcosine and beta-lactam antibiotics in human intestinal cell line Caco-2. Pharm Res 2003; 20: 1389-93.

7 Craig WA. Pharmacokinetic/pharmacodynamic parameters: rationale for antibacterial dosing of mice and men. Clin Infect Dis 1998; 26: 11-2.

8 Drusano GL. Antimicrobial pharmacodynamics: critical interactions of 'bug and drug'. Nat Rev Microbiol 2004; 2: 289-300.

9 Bhutta ZA, Black RE, Brown KH, Gardner JM, Gore S, Hidayat A, Khatun F, Martorell R, Ninh NX, Penny ME, Rosado JL, Roy SK, Ruel M, Sazawal S, Shankar A. Prevention of diarrhea and pneumonia by zinc supplementation in children in developing countries: pooled analysis of randomized controlled trials. Zinc Investigators' Collaborative Group. J Pediatr 1999; 135: 689-97.

10 Brown KH, Peerson JM, Rivera J, Allen LH. Effect of supplemental zinc on the growth and serum zinc concentrations of prepubertal children: a meta-analysis of randomized controlled trials. Am J Clin Nutr 2002; 75 : 1062-71.

11 Fischer WC, Black RE. Zinc and the risk for infectious disease. Annu Rev Nutr 2004; 24: 255-75. 
12 Saper RB, Rash R. Zinc: an essential micronutrient. Am Fam Physician 2009; 79: 768-72.

13 Walravens PA, Hambidge KM, Koepfer DM. Zinc supplementation in infants with a nutritional pattern of failure to thrive: a double-blind, controlled study. Pediatrics 1989; 83: 532-8.

14 Nakagawa T, Haginaka J, Yamaoka K, Uno T. High speed liquid chromatographic determination of cephalexin in human plasma and urine. J Antibiot (Tokyo) 1978; 31: 769-75.

15 Mallory SB. Azithromycin compared with cephalexin in the treatment of skin and skin structure infections. Am J Med 1991; 91:36S-9S.

16 Nightingale $\mathrm{CH}$. Antimicrobial Pharmacodynamics in Theory and Clinical Practice. New York: Informa Healthcare, 2007.

17 Saitoh H, Aungst BJ, Tohyama M, Hatakeyama Y, Ohwada K, Kobayashi M, Fujisaki H, Miyazaki K. In vitro permeation of beta-lactam antibiotics across rat jejunum and its correlation with oral bioavailability in humans. Br J Clin Pharmacol 2002; 54: 445-8.

18 Watkins DW, Chenu C, Ripoche P. Zinc inhibition of glucose uptake in brush border membrane vesicles from pig small intestine. Pflugers Arch 1989; 415: 165-71.

19 Rodriguez YM, Mesonero JE, Rodriguez YM. Effect of zinc on aminopeptidase $\mathrm{N}$ activity and L-threonine transport in rabbit jejunum. Biol Trace Elem Res 1996; 53: 213-23.

20 Ghishan FK, Said HM, Wilson PC, Murrell JE, Greene HL. Intestinal transport of zinc and folic acid: a mutual inhibitory effect. Am J Clin Nutr 1986; 43: 258-62.

21 Jaehde U, Sorgel F, Stephan U, Schunack W. Effect of an antacid containing magnesium and aluminum on absorption, metabolism, and mechanism of renal elimination of pefloxacin in humans. Antimicrob Agents Chemother 1994; 38: 1129-33.
22 Kamberi M, Nakashima H, Ogawa K, Oda N, Nakano S. The effect of staggered dosing of sucralfate on oral bioavailability of sparfloxacin. Br J Clin Pharmacol 2000; 49: 98-103.

23 Lober S, Ziege S, Rau M, Schreiber G, Mignot A, Koeppe P. Pharmacokinetics of gatifloxacin and interaction with an antacid containing aluminum and magnesium. Antimicrob Agents Chemother 1999; 43: 1067-71.

24 Lomaestro BM, Bailie GR. Quinolone-cation interactions: a review. DICP 1991; 25: 1249-58.

25 Polk RE, Healy DP, Sahai J, Drwal L, Racht E. Effect of ferrous sulfate and multivitamins with zinc on absorption of ciprofloxacin in normal volunteers. Antimicrob Agents Chemother 1989; 33: 1841-4.

26 Stass H, Kubitza D. Effects of iron supplements on the oral bioavailability of moxifloxacin, a novel 8-methoxyfluoroquinolone, in humans. Clin Pharmacokinet 2001; 40 (Suppl. 1): 57-62.

27 Stass H, Wandel C, Delesen H, Moller JG. Effect of calcium supplements on the oral bioavailability of moxifloxacin in healthy male volunteers. Clin Pharmacokinet 2001;40 (Suppl. 1): 27-32.

28 Campbell NR, Hasinoff BB. Iron supplements: a common cause of drug interactions. Br J Clin Pharmacol 1991; 31: 251-5.

29 Schaefer JP, Tam Y, Hasinoff BB, Tawfik S, Peng Y, Reimche L, Campbell NR. Ferrous sulphate interacts with captopril. Br J Clin Pharmacol 1998; 46: 377-81.

30 Madaras-Kelly KJ, Arbogast R, Jue S. Increased therapeutic failure for cephalexin versus comparator antibiotics in the treatment of uncomplicated outpatient cellulitis. Pharmacotherapy 2000; 20: 199-205.

31 Trumbo $P$, Yates AA, Schlicker S, Poos M. Dietary reference intakes: vitamin A, vitamin K, arsenic, boron, chromium, copper, iodine, iron, manganese, molybdenum, nickel, silicon, vanadium, and zinc. J Am Diet Assoc 2001; 101: 294-301. 